NHS

The Royal

Orthopaedic Hospital

NHS Foundation Trust

\title{
SURVEY OF ANAESTHETIC TECHNIQUES FOR KNEE ARTHROPLASTY: AT THE BRITISH SOCIETY OF ORTHOPAEDIC ANAESTHETISTS (BSOA) ANNUAL MEETING NOVEMBER 2017
}

\author{
B. Smith', O.Williams², R. Hutton², L. McFarlane-Majeed ${ }^{2}$, E. DaSilva ${ }^{3}$. \\ 'Anaesthetic Speciality Registrar, Royal Orthopaedic Hospital, Birmingham, United Kingdom. \\ 2Medical Student, University of Birmingham Medical School, Birmingham, United Kingdom. \\ ${ }^{3}$ Anaesthetic Consultant, Royal Orthopaedic Hospital, Birmingham, United Kingdom.
}

\section{Background and Aims:}

Total knee arthroplasty is a common and painful orthopaedic procedure ${ }^{1,2}$. Anaesthetic techniques have evolved with enhanced recovery programmes to improve postoperative pain control, aid in earlier mobilisation and reduce length of stay. Consensus in the literature regarding optimal anaesthetic technique is limited ${ }^{2,3}$. Therefore, we undertook a survey a group of anaesthetists who have a specialist interest in orthopaedic anaesthesia on preferred anaesthetic techniques, looking for consistent themes.

\section{Methods:}

Questionnaires were handed out to delegates at the BSOA Annual Scientific meeting, Prague. Data collected included country of anaesthetic practice and primary anaesthetic technique. For regional techniques, a breakdown of drug dosages and volumes were requested.

\section{Results:}

52 questionnaires were completed out of 216 Delegates (24\% return). Choice of primary anaesthetic technique showed preference for spinal anaesthesia with or without other nerve block (29/52). General anaesthetic was preferred by 20 out of 52 respondents with $40 \%$ of these also performing spinal anaesthesia. Adductor canal blocks were favoured over femoral and sciatic combinations (I5 vs 3). Spinal anaesthesia was performed slightly more often with isobaric than hyperbaric bupivacaine (56\% vs $36 \%$ ) and with opioid more than without (66\% vs $33 \%)$.

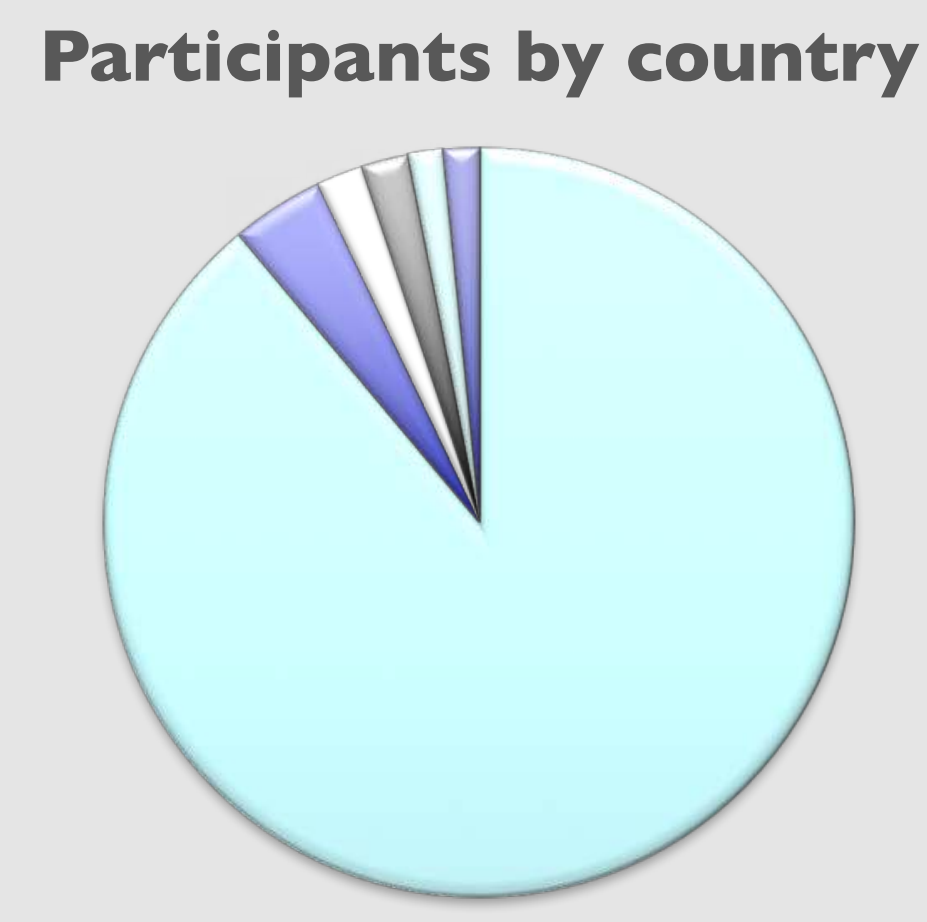

$\square$ United Kingdom $\square$ Czech Republic $\square$ Iraq $\square$ Poland $\square$ Australia $\quad$ U Ukraine
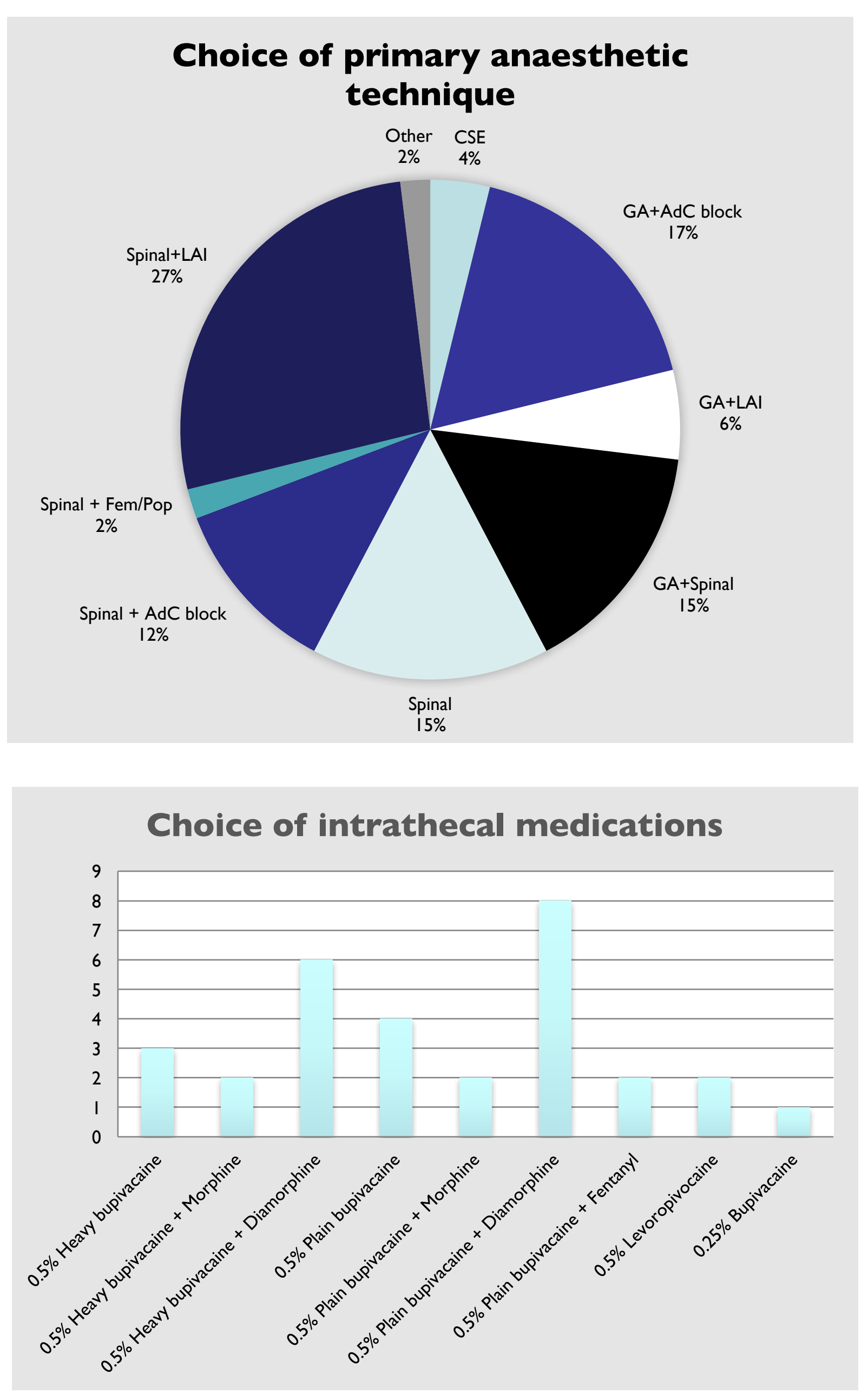

Conclusions:

This survey mirrors current literature, that no single anaesthetic technique is preferred to any other. For spinal anaesthesia there was marked variation in the choice of drug and additives used. Adductor canal blocks appear to be used more often than femoral nerve blocks, probably related to recent literature showing similar analgesia with less quadriceps spasticity and earlier mobilisation ${ }^{4}$. Whilst there is no perceived harm, is there mileage in standardisation of technique?

\section{References:}

I. C. J. L. McCartney, S. Choi. Does anaesthetic technique really matter for total knee arthroplasty? BJA: British Journal of Anaesthesia, Volume III, Issue 3, I September 2013, Pages 33I-333

2. Z. Turnbull, D. Sastow, G. Giambrone, et al. Anesthesia for the patient undergoing total knee replacement: current status and future prospects. Local Reg Anesth; 2017; 10: $1-7$

3. Royal College of Anaesthetists (2014) Anaesthetic choices for hip or knee replacement: Information for patients, $4^{\text {th }}$ Edition

4. I. J. Koh, Y. J. Choi, M. S. Kim, et al. Femoral Nerve Block versus Adductor Canal Block for Analgesia after Total Knee Arthroplasty; Knee Surg Relat Res. 2017 Jun; 29(2): 87-95. 